\title{
EFEITO DA TORTA DE NABO FORRAGEIRO SOBRE A CINÉTICA DE FERMENTAÇÃO E DEGRADAÇÃO RUMINAL IN VITRO
}

\section{EFFECT OF COTTONSEED MEAL REPLACEMENT BY RADISH CAKE ON THE RUMINAL FERMENTATION AND IN VITRO DEGRADATION KINETICS}

\author{
Fortaleza, A.P.S. ${ }^{*}$; Silva, L.D.F. ${ }^{\text {; }}$ Barbero, R.P. ${ }^{1}$; Barbosa, M.A.A.F. ${ }^{\text {; }}$ Prado, M.R. ${ }^{2}$ \\ e Calsamiglia, S.B. ${ }^{2}$
}

\begin{abstract}
'Departamento de Zootecnia. Universidade Estadual de Londrina. Londrina-PR. Brasil *anapaula_fortaleza@yahoo.com.br

2Departamento de Ciencia Animal y de los Alimentos. Campus de la UAB Bellaterra (Cerdanyola del Vallès). Barcelona. España.
\end{abstract}

\section{PaLAVRAS ChaVE ADICIONAIS}

Bovino. Co-produtos. Produção de gás.

\section{RESUMO}

Considerando a necessidade de dar destino correto aos co-produtos gerados no processo de produção do biodiesel, bem como caracterizar nutricionalmente fontes alternativas de proteína para bovinos, o objetivo deste trabalho foi avaliar os parâmetros ruminais e o valor nutritivo de rações contendo 0, 2, 4 e $8 \%$ de inclusão de torta de nabo forrageiro por meio da técnica in vitro semi-automática de produção de gases. A avaliação da cinética da degradação ruminal, digestibilidade da MS, MO e FDN, bem como as determinações de $\mathrm{pH}$, ácidos graxos voláteis e nitrogênio amoniacal foram realizadas por meio da incubação de $0,3 \mathrm{~g}$ de amostra em meio de cultura tamponado. Foi verificado efeito cúbico do nível de substituição sobre o volume de gás correspondente à completa digestão do substrato, com valores de 1,$69 ; 1,70 ; 1,53 ; 1,61 \mathrm{~mL} / \mathrm{mg} \mathrm{MS}$, respectivamente, para os níveis de 0,2 , 4 e $8 \%$ de inclusão. Houve efeito quadrático do nível de substituição do farelo de algodão pela torta de nabo forrageiro sobre a digestibilidade in vitro da MS, MO e FDN, com pontos de máxima em 2,$75 ; 2,70$ e 2,63 \% de torta de nabo forrageiro, respectivamente. A inclusão da torta de nabo forrageiro influenciou a concentração total de AGV, a concentração de nitrogênio amoniacal e a proporção molar de ácido acético e propiônico. A relação acetato:propionato e o pH não foram influenciados pela inclusão da torta de nabo forrageiro, apresentando valores

\author{
Additional KEYWORDS \\ Bovine. Co-products. Gas production.
}

médios de 3,36 e 6,93, respectivamente. Concluise que a inclusão de $2,63 \%$ de torta de nabo forrageiro proporcionou melhor digestibilidade da MS, MO e FDN das rações, sugerindo que a torta de nabo forrageiro pode ser utilizada em rações de bovinos de corte em substituição parcial ao farelo de algodão.

\section{SUMMARY}

Considering the need to give the correct destination to co-products generated in the production of biodiesel, as well as nutritionally characterize alternative sources of protein for cattle, the objective of this study was to evaluate ruminal parameters and nutritional value of diets containing $0,2,4$ and $8 \%$ replacement of cottonseed meal by radish cake utilizing a semi-automated in vitro gas production technique. The evaluation of rumen degradation kinetics, digestibility of $\mathrm{DM}, \mathrm{OM}$ and NDF, as well as $\mathrm{pH}$, volatile fatty acids and ammoniacal nitrogen determination were performed by incubating $0.3 \mathrm{~g}$ of sample in buffered medium. It was observed a cubic effect of the replacement level on the volume of gas corresponding to complete digestion of the substrate, with values of $1.69,1.70,1.53,1.61 \mathrm{~mL} / \mathrm{mg} \mathrm{DM}$, respectively, for levels $0,2,4$ and $8 \%$ of substitution. There was a quadratic effect of the level of cottonseed meal replacement by radish cake on the in vitro 
digestibility of DM, OM and NDF, with maximum points in $2.75,2.70$ and $2.63 \%$ of radish cake, respectively. The cottonseed meal replacement by radish cake influenced total concentration of VFA, concentration of ammoniacal nitrogen and the molar ratio of acetic and propionic acid. The acetate: propionate ratio and $\mathrm{pH}$ were not influenced by the substitution of cottonseed meal by radish cake, with average values of 3.36 and 6.93 , respectively. It is concluded that the replacement of $2.63 \%$ of the cottonseed meal by radish cake provided better digestibility of $\mathrm{DM}, \mathrm{OM}$ and NDF of the diets, suggesting that the radish cake can be used in rations of beef cattle, partially replacing the cottonseed meal.

\section{INTRODUÇÃO}

Com a obrigatoriedade, a partir de 2013, da inclusão de $5 \%$ de biodiesel ao óleo diesel comercializado em todo o território nacional (Brasil, 2005) ocorrerá aumento na produção dos farelos e das tortas, principais co-produtos da produção do biodiesel. Esses co-produtos, além de apresentarem grande impacto no custo total de produção do biodiesel (Barros et al., 2006), representam uma fonte alternativa para a alimentação dos ruminantes, contribuindo com a diminuição dos custos de produção, uma vez que a alimentação corresponde a, aproximadamente, $85 \%$ dos custos totais de produção (Coan et al., 2008).

Dentre as oleaginosas utilizadas para a extração de óleo para produção do biodiesel, o nabo forrageiro (Raphanus sativus L.) apresentou-se como uma cultura de grande interesse, sobretudo no estado do Paraná, em função da sua facilidade de produção e pelas condições de reciclagem de nutrientes no solo, reduzindo assim custos com adubação (Sluszz e Machado, 2006).

Diversos estudos (Barbero et al., 2008; Mello et al., 2008; Fortaleza, 2011) avaliaram a utilização da torta de nabo forrageiro no desempenho de bovinos e concluíram que este ingrediente pode substituir, parcialmente, fontes proteicas tradicionais. No entanto, poucos trabalhos avaliaram os parâmetros ruminais e o valor nutritivo deste ingrediente.

O valor nutritivo dos alimentos é determinado por uma complexa interação entre os nutrientes e os microrganismos do trato digestivo, nos processos de digestão, absorção, transporte e utilização de metabólitos (Martins et al., 2000).

Neste sentido, as técnicas in vivo, in situ e in vitro de avaliação dos alimentos são uma valiosa ferramenta para estimar o valor nutritivo dos alimentos. A técnica in vitro semi-automática de produção de gases (Mauricio et al., 1999) apresenta comprovado potencial em descrever a cinética da fermentação ruminal, fornecer a taxa e a extensão da degradação dos alimentos, bem como medir produtos da fermentação de partes solúveis e insolúveis dos substratos (Pell e Schofield, 1993). Além disso, Mauricio et al. (2003) demonstraram que é possível estimar a curva de degradação da MS por meio de valores da produção cumulativa de gases para grupos específicos de alimentos.

Assim, tendo em vista a necessidade de dar um destino correto aos co-produtos gerados no processo de produção do biodiesel, bem como caracterizar nutricionalmente fontes alternativas de proteína para bovinos, os objetivos deste trabalho foram avaliar os parâmetros ruminais e o valor nutritivo de rações contendo diferentes níveis de torta de nabo forrageiro em substituição ao farelo de algodão pela técnica in vitro semi-automática de produção de gases.

\section{MATERIALEMÉTODOS}

O preparo das rações experimentais e as análises bromatológicas dos ingredientes e das rações foram realizados no Laboratório de Análises e Nutrição Animal da Universidade Estadual de Londrina.

As análises dos teores de matéria seca (MS), matéria orgânica (MO), proteína bruta (PB), extrato etéreo (EE), fibra em deter- 


\section{EFEITO DA TORTA DE NABO FORRAGEIRO SOBRE PARÂMETROS RUMINAIS}

gente neutro (FDN) e fibra em detergente ácido (FDA) foram realizadas segundo procedimentos da AOAC (1990), modificados por Mizubuti et al. (2009). Os teores de NDT foram calculados a partir da equação proposta por Weiss (1993):

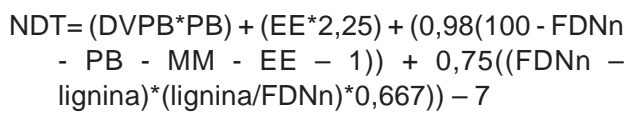

em que:

DVPB: corresponde à digestibilidade verdadeira da proteína bruta, que é calculada usando a proteína insolúvel em detergente ácido (PIDA), por intermédio da equação $\mathrm{DVPB}=\exp$ $\left(-0,012^{*}\right.$ PIDA);

FDNn: a fibra em detergente neutro corrigida para nitrogênio.

Os carboidratos totais foram estimados a partir da equação:

$$
C T=100-(P B+E E+M M)
$$

O fracionamento dos carboidratos foi realizado de acordo com a metodologia proposta por Sniffen et al. (1992).

O experimento de produção de gases e digestibilidade in vitro foram realizados nas instalações do Servei de Nutrició y Bienestar Animal da Universitat Autònoma de Barcelona, Espanha.

Foram analisadas quatro rações, com relação volumoso:concentrado 47:53, com
$0,2,4$ e $8 \%$ de inclusão de torta de nabo forrageiro, adicionada às rações em substituição à proteína bruta do farelo de algodão. As rações foram formuladas pelo Sistema Viçosa de Formulação de Rações (Lana, 2007) para atender as exigências de animais $1 / 2$ Europeu $+1 / 2 \mathrm{Zebu}_{2}$ com aproximadamente $240 \mathrm{~kg}$ de peso corporal, em fase de terminação. As composições químicas dos ingredientes e das rações experimentais encontram-se nas tabelas I e II, respectivamente.

As digestibilidades in vitro da matéria seca (DMS), matéria orgânica (DMO) e da fibra em detergente neutro (DFDN) foram obtidas após $48 \mathrm{~h}$ de fermentação em frascos com capacidade de $160 \mathrm{~mL}$, utilizandose meio de cultura de acordo com as recomendações de Theodorou et al. (1994). Aproximadamente $0,3 \mathrm{~g}$ de amostra foi introduzida nos frascos de fermentação e a esta foram acrescidos $30 \mathrm{~mL}$ de meio de cultura tamponado. O líquido ruminal utilizado foi obtido de uma vaca da raça Holandês, não lactante, provida de cânula ruminal permanente e adaptada à dieta proposta (47 $\%$ de volumoso e $53 \%$ de concentrado). Após a coleta o líquido ruminal foi filtrado em camada dupla de gaze e armazenado em garrafa térmica, previamente aquecida, até o momento da utilização no laboratório.

O ensaio de avaliação da cinética de degradação ruminal foi realizado em dois períodos. A pressão $(\mathrm{Pa})$ dos gases

Tabela I. Composição química dos alimentos (\% MS). (Chemical composition of the feedstuffs $(\%$ DM)).

\begin{tabular}{lccccccc}
\hline & MS & MO & PB & EE & FDN & FDA & NDT \\
\hline Silagem de sorgo & 27,89 & 95,50 & 6,90 & 5,40 & 68,70 & 45,70 & 48,81 \\
Milho & 87,60 & 95,80 & 11,50 & 4,60 & 10,60 & 9,10 & 81,28 \\
Farelo de algodão & 89,90 & 97,40 & 38,00 & 1,70 & 47,90 & 36,90 & 61,31 \\
Torta de nabo & 93,70 & 93,60 & 41,30 & 14,50 & 24,40 & 18,40 & 76,32
\end{tabular}

$M S=$ matéria seca; $M O=$ matéria orgânica; $P B=$ proteína bruta; $E E=$ extrato etéreo; $F D N=$ fibra em detergente neutro; FDA = fibra em detergente ácido; NDT= nutrientes digestíveis totais. 


\section{FORTALEZA, SILVA, BARBERO, BARBOSA, CALSAMIGLIA E PRADO}

produzidos no interior dos frascos de fermentação foi obtida com um manômetro digital (Delta OHM ${ }^{\circledR}$ HD8804) e, posteriormente convertidas em volume ( $\mathrm{mL})$.

Para cada um dos tratamentos foram incubados 16 frascos (oito por período), além de dois frascos brancos, apenas com meio de cultura, utilizados como controle. Estes frascos foram lacrados com tampa de borracha e lacre de alumínio e, posteriormente, uma agulha $(25,0 \times 0,7 \mathrm{~mm})$ foi inserida em cada frasco perspassando-se as tampas de borracha, possibilitando o equilíbrio entre a pressão interna dos frascos e a pressão atmosférica. Os frascos foram mantidos a $39{ }^{\circ} \mathrm{C}$ em banho-maria. As mensurações das pressões dos gases foram realizadas nos horários 0,$5 ; 1 ; 2 ; 4 ; 6 ; 8 ; 10$; $12 ; 15 ; 18 ; 21 ; 24 ; 30 ; 36$ e 48 h pós-incubação.
Os resíduos de fermentação foram obtidos por meio da filtragem do conteúdo dos frascos de fermentação em cadinho de fundo poroso (100 a $160 \mu \mathrm{m})$ sob vácuo. Os cadinhos foram secos por $24 \mathrm{~h}$ a $105^{\circ} \mathrm{C}$ e posteriormente incinerados em mufla a 500 ${ }^{\circ} \mathrm{C}$ para determinação dos valores de DMS e DMO. O fator de partição foi calculado pela divisão da quantidade de MO degradada $(\mathrm{mg})$ pelo volume de gases $(\mathrm{mL})$ produzidos após $48 \mathrm{~h}$ de fermentação. A determinação da DFDN foi obtida pela filtragem do resíduo de fermentação em bolsas de náilon, posteriormente lacradas a quente. $\mathrm{O}$ resíduo foi analisado de acordo com os procedimentos da AOAC (1990) utilizando-se o aparelho Ankon $^{200}$ (Ankon Technology Corp., Fairport, NY, USA).

Para a determinação do $\mathrm{pH}$, ácidos graxos

Tabela II. Composição percentual e química das rações experimentais. (Percentage and chemistry composition of experimental diets).

\begin{tabular}{lcccc}
\hline & \multicolumn{3}{c}{ Torta de nabo forrageiro (\%) } \\
& 0 & 2 & 4 & 8 \\
\hline Alimentos & & & & \\
Silagem de sorgo & 47,00 & 47,00 & 47,00 & 47,00 \\
Milho triturado & 40,83 & 41,53 & 41,40 & 40,31 \\
Farelo de algodão & 10,67 & 7,90 & 5,66 & 3,34 \\
Torta de nabo forrageiro & - & 2,07 & 4,44 & 7,85 \\
$\quad$ Suplemento Mineral & 1,00 & 1,00 & 1,00 & 1,00 \\
Bicarbonato de sódio & 0,50 & 0,50 & 0,50 & 0,50 \\
Composição nutricional (\%MS) & & & & \\
Matéria seca & 58,62 & 58,69 & 58,79 & 59,04 \\
Matéria orgânica & 94,20 & 94,19 & 94,15 & 94,05 \\
Proteína bruta & 11,10 & 11,03 & 11,20 & 11,75 \\
Extrato etéreo & 4,19 & 4,45 & 4,72 & 5,09 \\
Fibra em detergente neutro & 45,19 & 44,35 & 43,78 & 43,34 \\
Carboidratos totais & 78,91 & 78,72 & 78,24 & 77,32 \\
Nutrientes digestíveis totais & 62,67 & 63,12 & 63,45 & 64,74 \\
Fracionamento dos carboidratos totais (\%CT) & & & & \\
A+B1 & 57,12 & 57,58 & 57,38 & 56,91 \\
B2 & 32,39 & 32,52 & 32,84 & 33,49 \\
C & 10,49 & 9,90 & 9,78 & 9,60 \\
\hline
\end{tabular}

$\mathrm{A}=$ fração prontamente fermentada no rúmen; $\mathrm{B} 1$ = fração com taxa de degradação intermediária; $\mathrm{B} 2=$ fração de lenta degradação e potencialmente digerível da parede celular; $\mathrm{C}=$ fração indigerível. 
voláteis (AGV) e nitrogênio amoniacal (N$\mathrm{NH}_{3}$ ), foram incubados, em banho maria, quatro frascos (dois por período). A incubação foi realizada como descrito anteriormente, no entanto, nestes frascos não foram realizadas as mensurações das pressões dos gases. Após $24 \mathrm{~h}$ de incubação, os frascos foram abertos e o líquido de incubação foi coletado após filtragem dos resíduos sendo o $\mathrm{pH}$ mensurado com um potenciômetro digital. Uma subamostra de $4 \mathrm{~mL}$ do líquido de incubação de cada frasco foi coletado, acidificado com $4 \mathrm{~mL}$ de ácido clorídrico $0,2 \mathrm{~N}$ e congelado. Posteriormente as amostras foram centrifugadas a 25000 g por 20 minutos e o sobrenadante foi analisado para N-NH . Para determinação dos AGV, as amostras foram preparadas como descrito por Jouany (1982) utilizando ácido 4-metilvalérico como padrão interno. A análise foi realizada no Servei d'Anàlisis Químiques da Universitat Autònoma de Barcelona, Espanha, por cromatógrafo de gases (modelo 6890, Hewlett Packard, Palo Alto, CA) utilizando coluna de polietilenoglicol (BP21, SGE, Europe Ltd., Buckinghamshire, Inglaterra).

O modelo matemático de Gompertz foi utilizado para a avaliação da cinética de fermentação,

$Y t=a^{*} \exp ^{(-b)^{*} \exp \left(-c^{*} t\right)}$

sendo:

$\mathrm{Yt}=$ volume de gás no tempo $(\mathrm{mL})$;

$\mathrm{a}=$ volume de gás correspondente à completa digestão do substrato (assíntota) (mL/mg MS);

$\mathrm{b}=$ taxa específica semelhante à taxa de degradação (\%/h);

$\mathrm{c}=$ fator constante de eficiência microbiana, que descreve o ponto de inflexão da curva a uma determinada velocidade de produção de gás $(\mathrm{mL} / \mathrm{h})$,

$\mathrm{t}=$ tempo de incubação $(\mathrm{h})$.

O procedimento não linear do SAS (1994) foi utilizado para ajustar os dados ao modelo.

Os dados obtidos foram submetidos à análise de variância e regressão por meio de um modelo inteiramente casualizado, tendo como variáveis independentes os teores de inclusão da torta de nabo forrageiro, o período e a interação entre os teores de inclusão e o período utilizando-se o pacote estatístico SAS (1994).

\section{RESULTADOSEDISCUSSÃO}

Não houve efeito do período ou da interação entre os teores de inclusão e o período para as variáveis analisadas, sendo assim os resultados apresentados se referem ao efeito do teor de inclusão da torta de nabo forrageiro.

O volume de gás correspondente à completa digestão do substrato apresentou efeito cúbico em função dos teores de inclusão da torta de nabo forrageiro (tabela III). Uma vez que a técnica de produção de gases mensura os gases produzidos como resultado da degradação principalmente de carboidratos, sendo que a contribuição dos gases resultante da degradação da proteína é relativamente pequena, esse comportamento pode ser justificado pela composição química das rações experimentais (tabela II). Assim sendo, esperava-se que a inclusão de torta de nabo forrageiro aumentasse a produção de gases, uma vez que houve aumento na quantidade de carboidratos potencialmente degradáveis. No entanto, no presente estudo parece que a elevada quantidade de ácidos graxos polinsaturado $(60,7 \%)$ presentes na torta de nabo forrageiro (Dambiski, 2007), influenciou negativamente a degradação das rações com maiores teores de inclusão de torta de nabo forrageiro, uma vez que a maior produção de gás foi observada com a inclusão de $1 \%$ de torta de nabo forrageiro $(1,74 \mathrm{~mL} / \mathrm{mg} \mathrm{MS}) \mathrm{e}$ a menor com a inclusão de $6 \%(1,41 \mathrm{~mL} / \mathrm{mg}$ MS).

Para a taxa constante de produção de gás do material potencialmente degradado e para o fator de eficiência microbiana, calculados de acordo com o modelo de Gompertz, não foi verificado efeito signifi- 


\section{FORTALEZA, SILVA, BARBERO, BARBOSA, CALSAMIGLIA E PRADO}

cativo da inclusão da torta de nabo forrageiro na ração.

Baixa produção de gases por um determinado alimento não indica que este é um alimento de baixo valor nutritivo. É necessário correlacionar a produção de gás com o desaparecimento do substrato incubado para uma correta interpretação. $\mathrm{O}$ fator de partição correlaciona essas duas variáveis, pois é definido como a razão entre a $\mathrm{MO}$ degradada e o volume de gás produzido pela fermentação, sendo assim, um indicador da eficiência fermentativa (Blümmel et al., 1997).

A inclusão da torta de nabo forrageiro nas rações influenciou o fator de partição (tabela III) que apresentou efeito cúbico, com maior fator de partição com a inclusão de $5,91 \%$ de torta de nabo forrageiro, indicando que, para este teor de inclusão, maior quantidade de MO degradada foi incorporada à massa microbiana, ou seja, a eficiência de síntese de proteína microbiana foi maior e as perdas por gases foram menores, o que, de acordo com Blümmel et al. (2005), pode indicar maior consumo de alimento.

Abdalla et al. (2008) verificaram correlação negativa entre o fator de partição e a produção de metano ao realizar ensaio in vitro com o objetivo de estudar a inclusão de tortas e farelos oriundos da cadeia do biodiesel na dieta de ruminantes. De acordo com os autores, essa correlação pode ser explicada pela composição química desses alimentos que, sendo ricos em ácidos graxos polinsaturados, proporcionou aumento na biohidrogenação ruminal. Durante esse processo, há consumo de hidrogênio, contribuindo para a redução da produção de metano pelas bactérias metanogênicas e aumento da eficiência energética da dieta.

A relação entre a produção de gases às $48 \mathrm{~h}$ e o volume total de gases correspondente à completa digestão do alimento é usada para estimar se o ensaio de produção de gases foi suficientemente longo para que o potencial máximo de degradação do alimento fosse atingido (Azevedo et al., 2009). O ideal é que essa relação seja próxima da unidade, indicando que o potencial de produção de gases foi alcançado durante o ensaio e que a avaliação permite boa interpretação dos perfis de degradação dos alimentos. Neste estudo, esta relação esteve entre 0,98 e 0,99 , ou seja, foi possível atingir de 98 a $99 \%$ do potencial de degradação do alimento durante o ensaio de produção de gases.

Tabela III. Médias, equações de regressão (ER) e coeficiente de determinação $\left(R^{2}\right)$ para os parâmetros de fermentação ruminal em função dos teores de torta de nabo forrageiro na ração. (Means, regression equations (ER) and coefficient of determination $\left(\mathrm{R}^{2}\right)$ for the parameters of rumen fermentation in relation to levels of radish cake in the diets).

\begin{tabular}{|c|c|c|c|c|c|c|c|}
\hline & \multicolumn{4}{|c|}{ Torta de nabo forrageiro (\%) } & \multirow[b]{2}{*}{ CV (\%) } & \multirow[b]{2}{*}{ ER } & \multirow[b]{2}{*}{$\mathrm{R}^{2}$} \\
\hline & 0 & 2 & 4 & 8 & & & \\
\hline a (mL/mg MS) & 1,69 & 1,70 & 1,53 & 1,61 & 6,85 & ER1 & 0,43 \\
\hline$b\left(\% h^{-1}\right)$ & 0,102 & 0,106 & 0,114 & 0,104 & 10,65 & $Y=0,106$ & - \\
\hline c & 4,20 & 4,23 & 4,98 & 4,32 & 17,66 & $Y=4,430$ & - \\
\hline Fator de partição & 1,87 & 1,82 & 2,08 & 1,89 & 6,24 & ER2 & 0,71 \\
\hline REL & 0,99 & 0,98 & 0,98 & 0,99 & 2,06 & $Y=0,986$ & - \\
\hline
\end{tabular}

$R E L=$ relação entre produção de gás às $48 \mathrm{~h}$ e o volume de gás correspondente a completa digestão do substrato; $a=$ volume de gás correspondente à completa digestão do substrato; $b=$ taxa constante de produção de gás do material potencialmente degradado; $c=$ fator constante de eficiência microbiana. $E R 1: Y=1,69+0,095201 x-0,055201 x^{2}+0,005256 x^{3} ; E R 2: Y=1,87-0,1772 x+0,092216 x^{2}-0,008713 x^{3}$.

Archivos de zootecnia vol. 62, núm. 237, p. 136. 


\section{EFEITO DA TORTA DE NABO FORRAGEIRO SOBRE PARÂMETROS RUMINAIS}

Na comparação da produção cumulativa de gases (figura 1), ocorreu aumento significativo na produção de gases $(\mathrm{mL})$ no decorrer do processo de degradação. Porém, as produções acumuladas de gases demonstraram tendência à estabilização após $30 \mathrm{~h}$ de incubação, demonstrando, uma vez mais, que o tempo máximo de incubação $(48 \mathrm{~h})$ foi suficiente para que ocorresse a degradação de todos os nutrientes potencialmente degradáveis.

As curvas de produção cumulativa de gases para as rações estudadas (figura 1) apresentaram forma sigmóide, forma geralmente apresentada para as curvas de produção cumulativa de gases em estudos de degradação in vitro (Pell et al., 1997), o que possibilita a utilização do modelo de Gompertz para estimar a produção de gases (Farias et al., 2011). As curvas de produção cumulativa foram semelhantes para as quatro rações avaliadas (figura 1) sendo possível observar três fases: fase inicial com ausência ou lenta produção de gases (período de 0 a 6 h), envolvendo aderência e colonização microbiana; fase exponencial com rápida produção de gases (6 a 30 h), representando a degradação enzimática; e fase assintótica com diminuição na taxa de produção de gases (a partir das $30 \mathrm{~h}$ ). Nogueira (2011) ao avaliar as tortas da polpa e da amêndoa do dendê, também verificou que as curvas de produção cumulativa de gases apresentaram forma sigmóide, independente do inóculo utilizado, líquido ruminal bovino ou ovino. No entanto, a fase inicial observada por esse autor se estendeu até as $12 \mathrm{~h}$, provavelmente em função do alto teor de FDN dos alimentos avaliados, 61,2 e 68,5 , respectivamente para a polpa e amêndoa do dendê.

As curvas das taxas de produção de gases $(\mathrm{mL} / \mathrm{h})$ para todas as rações experimentais (figura 2) apresentaram dois picos: às 12 e 18 h de incubação. Maurício et al. (2003) observaram dois picos para a produção de gases em silagens de quatro híbridos de sorgo, às 8 h e entre 16 e 24 h, atribuindo esse fato à fermentação dos carboidratos solúveis na fase inicial da fermentação e à fermentação dos carboidratos fibrosos posteriormente. $\mathrm{O}$ atraso no pico de produção de gás observado neste estudo parece ser conseqüência do maior teor de extrato etéreo das rações em relação às silagens de sorgo, o que pode dificultar

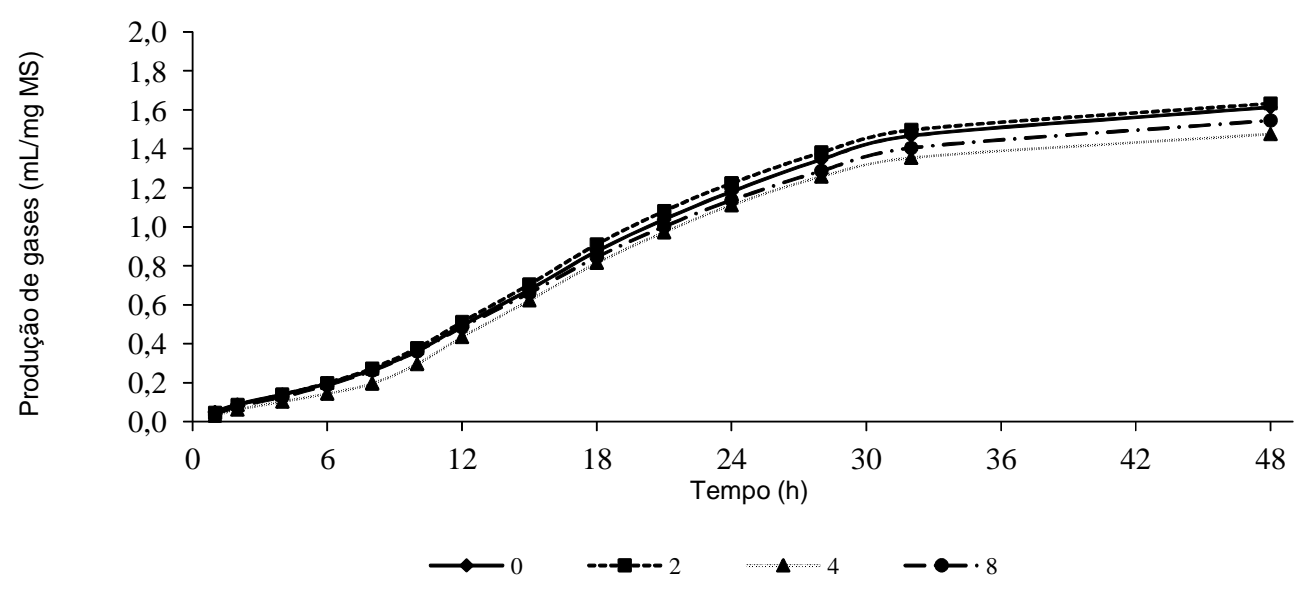

Figura 1. Produção cumulativa de gases ( $\mathrm{mL} / \mathrm{mg} \mathrm{MS}$ ) em função dos teores de torta de nabo forrageiro na ração. (Cumulative gas production $(\mathrm{mL} / \mathrm{mg} \mathrm{DM})$ in relation to level of radish cake in the diets). 


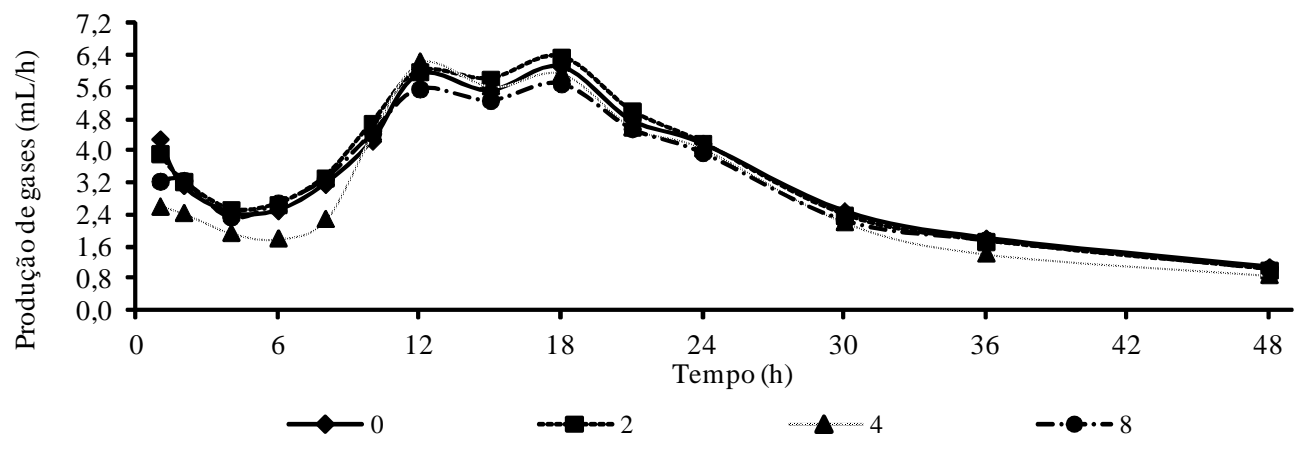

Figura 2. Taxa de produção de gases $(\mathrm{mL} / \mathrm{h})$ em função dos teores de substituição do farelo de algodão por torta de nabo forrageiro na ração. (Rate of gas production $(\mathrm{mL} / \mathrm{h})$ in relation to level of radish cake in the diets).

a adesão dos microrganismos às partículas de alimento em virtude da capacidade adsortiva dos ácidos graxos (Doreau e Chilliard, 1997).

Para os coeficientes de digestibilidades in vitro da MS, MO e FDN foi verificado efeito quadrático do teor de inclusão da torta de nabo forrageiro nas rações (tabela IV). Barbero et al. (2007) também verificaram influência na digestibilidade da MO com a inclusão de torta de nabo forrageiro em substituição ao farelo de soja, com valores de 64,$64 ; 66,76 ; 63,78 ; 65,58$ e $63,25 \%$ para $0,25,50,75$ e $100 \%$ de substituição, respectivamente. Os autores atribuíram esse efeito a maior porcentagem de extrato etéreo das rações.

Efeito negativo sobre a digestibilidade da MS também foi relatado por Neiva Junior et al. (2010) ao avaliarem a digestibilidade in vitro da silagem de capim-elefante aditivada com 5,8 e $11 \%$ de torta de nabo forrageiro. Os elevados teores de FDN e FDA da torta de nabo forrageiro influenciaram, de acordo com os autores, a digestibilidade da MS, bem como a produção de gases potencial.

A torta de nabo, em decorrência do seu elevado teor de PB e EE, pode ser considerada como alimento proteico de elevado valor energético (Fortaleza et al., 2009) e sua inclusão em rações para ruminantes contribui para o aumento da densidade energética destas rações, aumentando a eficiência líquida do uso de energia em decorrência do menor incremento calórico. $\mathrm{No}_{\text {entanto }}$ a inclusão de lipídios na dieta de ruminantes como forma de permitir alto consumo de energia nem sempre é um método eficiente, uma vez que altos níveis deste componente nutritivo podem reduzir a digestão da MS no rúmen e resultar em menor disponibilidade de energia, causando distúrbios na fermentação ruminal e aumentando as perdas de energia nas fezes.

Neste trabalho os coeficientes de digestibilidade da MS, MO e FDN foram máximos quando o teor de inclusão foi de, respectivamente, 2,$75 ; 2,70$ e $2,63 \%$. De acordo com Doreau e Chilliard (1997) a magnitude da redução da digestibilidade dos componentes da parede celular está relacionada não só à quantidade, mas principalmente ao tipo de ácido graxo, sendo que os lipídios ricos em ácidos graxos insaturados tendem a provocar maior depressão na digestibilidade. Isto ocorre em virtude da alta capacidade reativa destes ácidos graxos com as membranas celulares, processo que normalmente resulta em perda da sua natureza bifásica, provocando a morte da célula microbiana, sendo as bactérias metanogênicas, Gram positivas e os 


\section{EFEITO DA TORTA DE NABO FORRAGEIRO SOBRE PARÂMETROS RUMINAIS}

protozoários os mais suscetíveis. O óleo proveniente do nabo forrageiro apresenta $60,7 \%$ de ácidos graxos insaturados (Dambiski, 2007), o que justifica a diminuição significativa na digestibilidade da FDN nas rações com maiores inclusões de torta de nabo forrageiro.

A maior digestibilidade da MS, MO e FDN com os teores intermediários de inclusão da torta de nabo forrageiro pode ser justificada pelas características nutricionais dos ingredientes protéicos. De acordo com Carrera (2010) a torta de nabo forrageiro apresenta maior digestibilidade da MS (79,39vs. 84,65\%) e daFDN (88,35 vs. $89,10)$ em relação ao farelo de algodão, no entanto a maior quantidade de ácidos graxos insaturados da torta de nabo forrageiro, influenciou negativamente a digestibilidade das rações com maiores teores de inclusão deste alimento.

$\mathrm{O}$ pH ruminal está diretamente relacio- nado com os produtos finais da fermentação e também com a taxa de crescimento dos microrganismos ruminais. A faixa de $\mathrm{pH}$ para que a atividade microbiana ocorra normalmente no rúmen é de 6,7 $\pm 0,5$ (Van Soest, 1994). Ørskov (1988) relatou que, em situações de pH abaixo de 6,2, ocorre redução na digestão da fibra devido à sensibilidade das bactérias fibrolíticas e o ponto ótimo da digestão da fibra ocorreu em valores de $\mathrm{pH}$ entre 6,7 e 7,1. Neste estudo a média do pH foi de 6,93 (tabela IV), o que permite inferir que a redução na digestibilidade dos componentes nutritivos não foi em decorrência do $\mathrm{pH}$ do meio.

A concentração total de $\mathrm{AGV}$ apresentou efeito cúbico em função dos teores de inclusão da torta de nabo forrageiro (tabela IV), com máxima concentração de AGV com a inclusão de 1,95 \% de torta de nabo forrageiro, comportamento semelhante ao observado para o volume de gás corres-

Tabela IV. Médias, equações de regressão (ER) e coeficiente de determinação $\left(R^{2}\right)$ para digestibilidade in vitro, $\mathrm{pH}$, concentração de ácidos graxos voláteis e $\mathrm{N}$-amoniacal em função dos teores de torta de nabo forrageiro na ração. (Means, regression equations (ER) and coefficient of determination $\left(\mathrm{R}^{2}\right)$ for in vitro digestibility, $\mathrm{pH}$, volatile fatty acids and ammonia-N in relation to level of radish cake in the diets).

\begin{tabular}{lcccccccc}
\hline & \multicolumn{7}{c}{ Torta de nabo } & \multicolumn{7}{c}{ forrageiro $(\%)$} & & & \\
& 0 & 2 & 4 & 8 & CV (\%) & ER & $R^{2}$ \\
\hline Matéria seca (\%) & 58,05 & 59,53 & 60,42 & 50,80 & 3,93 & ER1 & 0,82 \\
Matéria orgânica (\%) & 62,11 & 62,66 & 63,96 & 56,11 & 3,27 & ER2 & 0,78 \\
Fibra em detergente neutro (\%) & 64,27 & 68,99 & 65,32 & 57,71 & 2,87 & ER3 & 0,79 \\
pH & 6,87 & 6,94 & 6,95 & 6,98 & 2,87 & Y=6,93 & - \\
Ácidos graxos voláteis (mM) & 73,60 & 80,82 & 76,45 & 73,23 & 8,60 & ER4 & 0,22 \\
Acético (\%) & 60,45 & 60,70 & 60,02 & 62,03 & 1,57 & ER5 & 0,45 \\
Propiônico (\%) & 19,17 & 17,70 & 19,45 & 17,17 & 12,43 & ER6 & 0,38 \\
Butírico (\%) & 17,05 & 18,08 & 17,17 & 17,48 & 8,30 & Y=17,44 & - \\
Valérico (\%) & 1,02 & 1,06 & 1,02 & 1,02 & 2,45 & Y=1,03 & - \\
Acético:Propiônico & 3,22 & 3,51 & 3,11 & 3,61 & 13,51 & Y=3,36 & - \\
Ácidos graxos de cadeira ramificada & 2,32 & 2,46 & 2,34 & 2,30 & 6,96 & Y=2,32 & - \\
N-amoniacal & 25,52 & 24,07 & 24,64 & 24,59 & 14,54 & ER7 & 0,49 \\
\hline
\end{tabular}

ER1: $Y=57,79+1,9124 x+0,3469 x^{2} ; E R 2: Y=61,76+1,4427 x-0,2668 x^{2} ; E R 3: Y=64,94+1,7954 x-0,3411 x^{2}$; ER4: $Y=73,61+8,1902 x-2,7096 x^{2}+0,2100 x^{3}$; ER5: $Y=60,45+0,6181 x-0,3098 x^{2}+0,0321 x^{3} ; E R 6: Y=$ $19,17-2,1753 x+0,8819 x^{2}-0,08016 x^{3}$ ER7: $Y=25,52-1,5325 x+0,4788 x^{2}-0,0378 x^{3}$. 


\section{FORTALEZA, SILVA, BARBERO, BARBOSA, CALSAMIGLIA E PRADO}

pondente à completa digestão do substrato (tabela III). Alguns autores (Getachew et al., 1998; Moreira et al., 2009) relataram acentuada correlação entre a produção de AGV e o volume de gases produzidos in vitro, o que explicaria esse comportamento. Para as proporções molares de ácido acético e propiônico foi verificado efeito cúbico do teor de inclusão da torta de nabo forrageiro, no entanto a relação acético: propiônico não foi influenciada por essa inclusão. As maiores proporções molares de ácido propiônico ocorreram com a inclusão de $5,76 \%$ de torta de nabo forrageiro. Consequentemente, a produção de gases foi menor para este nível de inclusão (ponto de mínima produção de gases foi obtido com a inclusão de $5,8 \%$ de torta de nabo forrageiro). Isto ocorre, pois, pela estequiometria da fermentação ruminal, quando há produção de ácido propiônico não ocorrem perdas de energia na forma de $\mathrm{CO}_{2} \mathrm{e} \mathrm{CH}_{4}$.

A concentração de $\mathrm{N}-\mathrm{NH}_{3}$ apresentou efeito cúbico em função dos teores de inclusão da torta de nabo forrageiro (tabela IV). O ponto de máxima e mínima concentração de $\mathrm{N}-\mathrm{NH}_{3}$ foi obtido com a inclusão de, respectivamente, 2,14 e $6,30 \%$ de torta de nabo forrageiro e, em ambos, as concentrações foram superiores a $5 \mathrm{mg} / 100 \mathrm{~mL}$, considerada como ideal para o máximo crescimento microbiano (Satter e Slytter, 1974), o que indica que a disponibilidade de nitrogênio não foi um fator limitante para o crescimento dos microrganismos responsáveis pela degradação de carboidratos estruturais.

A concentração ruminal de amônia e de

\section{BIBLIOGRAFIA}

AOAC. 1990. Official methods of analysis. 15 ed. Association of Official Analytical Chemistry. Washington.

Abdalla, A.L.; Silva Filho, J.C.; Godoi, A.R.; Carmo, C.A. e Eduardo, J.L.P. 2008. Utilização de subprodutos da industria de biodiesel na ácidos graxos voláteis de cadeia ramificada, como isovalerato, isobutirato e 2-metil butirato são indicativos da fermentação ruminal de aminoácidos. Vargas et al. (2002) encontraram boas correlações entre os níveis de isovalerato, isobutirato e amônia $(\mathrm{r}>0,50)$, confirmando esta observação. Neste estudo a concentração de amônia apresentou efeito cúbico em função da inclusão de torta de nabo forrageiro, com ponto de mínima e de máxima, respectivamente, com a inclusão de 2,0 e 6,3\% deste alimento, porém a concentração de ácidos graxos voláteis de cadeia ramificada não foi influenciada pela inclusão da torta de nabo forrageiro (tabela IV). Esses resultados parecem indicar que a inclusão de 2 a $6 \%$ de torta de nabo forrageiro favorecem o crescimento das bactérias Gram positivas, fermentadoras obrigatórias de aminoácidos para suprir suas necessidades energéticas e protéicas, levando a maior produção de amônia, no entanto, em teores mais elevados de inclusão parece haver efeito direto dos ácidos graxos insaturados da torta de nabo forrageiro sobre estas bactérias em virtude de sua natureza apolar como relatado por Chalupa et al. (1984).

\section{CONCLUSÕES}

A inclusão de 2,63\% de torta de nabo forrageiro proporcionou melhor digestibilidade da MS, MO e FDN das rações, resultando em menores perdas de energia na forma de gases durante o processo de degradação, sugerindo que a torta de nabo forrageiro pode ser utilizada em rações de bovinos de corte em substituição parcial ao farelo de algodão.

alimentação de ruminantes. Rev Bras Zootecn, 37: 260-268.

Azevedo, M.M.R.; Vasconcelos, V.R.; Pimentel, J.C.M.; Pinto, B.I.S.; Araújo Neto, J.C. e Carvalho, A.A. 2009. Dinâmica de fermentação ruminal in vitro do pseudofruto de cinco clones de cajueiro. 


\section{EFEITO DA TORTA DE NABO FORRAGEIRO SOBRE PARÂMETROS RUMINAIS}

Rev Bras Zootecn, 38: 752-759.

Barbero, R.P.; Silva, L.D.F.; Massaro Junior, F.L.; Fortaleza, A.P.S.; Castro, V.S; Souza, R.S.; Alves, K.R.; Freitas Junior, J.G.; Beran, F.H.B.; Cavani, L. e Castro, F.A.B. 2007. Consumo e digestibilidades totais da matéria seca, matéria orgânica e proteína bruta em bovinos de corte em resposta a níveis de torta de nabo forrageiro em substituição ao farelo de soja. In: $13^{\circ}$ Congresso Brasileiro de Zootecnia. Londrina. Anais... ABZ. Brasília.

Barbero, R.P.; Fortaleza, A.P.S; Massaro Júnior, F.L.; Barbosa, M.A.A.F. e Silva, L.D.F. 2008. Suplementação de novilhas mestiças a pasto com torta de nabo forrageiro em comparação a diferentes fontes proteicas. In: 45 Anual da Sociedade Brasileira de Zootecnia. Lavras. Anais... SBZ. Viçosa.

Barros, G.S.C.; Silva, A.P.; Ponchio, L.A.; Alves, L.R.A.; Osaki, M. e Cenamo, M. 2006. Custos de produção de biodiesel no Brasil. Rev Pol Agríc, 15: 36-50. <http://www.agricultura.gov.br/pls/ portal/docs/PAGE/MAPA/MENU_LATERAL/ AGRICULIURA PECUARIA/ESTUDOS PUBLI CACOES/POLITICA_AGRICOLA/POLITICA AGRICOLA_PRINCIPAL/POL_AGR_03-2006_2. $P D F>(15 / 05 / 2010)$.

Blümmel, M.; Cone, J.W.; Van Gelder, A.H.; Nshalai, I.; Umunna, N.N.; Makkar, H.P.S. and Becker, K. 2005. Prediction of forage intake using in vitro gas production methods: comparison of multiphase fermentation kinetics measured in an automated gas test, and combined gas volume and substrate degradability measurements in a manual syringe system. Anim Feed Sci Tech, 123: $517-526$

Blümmel, M.; Steingab, H. and Becker, K. 1997. The relationship between in vitro gas production, in vitro microbial biomass and ${ }^{15} \mathrm{~N}$ incorporation and its implications for the prediction of voluntary feed intake of roughages. BrJ Nutr, 77: 911-921.

Brasil. 2005. Lei no 11097, de 13 de janeiro de 2005. Dispõe sobre a introdução do biodiesel na matriz energética brasileira; Altera as leis 9478 , de 6 de agosto de 1997, 9847, de 26 de outubro de 1999 e 10 636, de 30 de dezembro de 2002; e da outras providencias. Diário Oficial da União. Brasília, seção 1, p. 8, 14 jan.

Carrera, R.A.B. 2010. Caracterização de coprodutos e subprodutos protéicos da indústria do biodiesel para alimentação de ruminantes. Dissertação (Mestrado em Zootecnia). Curso de Pós-graduação em Zootecnia. Universidade Federal de Viçosa. 40 pp.

Chalupa, W.; Rickabaugh, B.; Kronfeld, D.S. and Sklan, D. 1984. Rumen fermentation in vitro as influenced by long chain fatty acids. J Dairy Sci, 67: 1439-1444.

Coan, R.M.; Reis, R.A.; Resende, F.D.; Sampaio, R.L.; Schocken-Iturrino, R.P.; Garcia, G.R. e Berchielli, T.T. 2008. Viabilidade econômica, desempenho e características de carcaça de garrotes em confinamento alimentados com dietas contendo silagem de capins Tanzânia ou marandu ou silagem de milho. Rev Bras Zootecn, 37: 311-318.

Dambiski, L. 2007. Síntese de biodiesel de óleo de nabo forrageiro empregando metanol supercrítico. Dissertação (Mestrado em Mecânica e de Materiais). Curso de Pós-graduação em Engenharia Mecânica e de Materiais. Universidade Tecnológica Federal do Paraná. 97 pp.

Doreau, M. and Chilliard, Y. 1997. Digestion and metabolismo of dietary fat in farm animals. Brit J Nutr, 78 suppl 1: 15-35.

Farias, L.N; Vasconcelos, V.R.; Carvalho, F.F.R. e Sarmento, J.L.R. 2011. Avaliação dos modelos logísticos bicompartimental e de Gompertz na estimativa da dinâmica de ferementação ruminal in vitro do farelo e da torta de babaçu. Arq Bras Med Vet Zootec, 63: 136-142.

Fortaleza, A.P.S.; Silva, L.D.F; Ribeiro, E.L.A.; Barbero, R.P.; Massaro Júnior, F.L.; Santos, A.X.; Castro, V.S. e Castro, F.A.B. 2009. Degradabilidade ruminal in situ dos componentes nutritivos de alguns suplementos concentrados usados na alimentação de bovinos. Semina: Ci. Agr., 30: 481-496. <http:// www.uel.br/portal/frm/frmOpcao.php?opcao= http://www.uel.br/revistas/uel/index. php/ semagrarias> (15/11/2009).

Fortaleza, A.P.S. 2011. Torta de nabo forrageiro: valor nutritivo, ingestão, desempenho e características de carcaça e da carne de novilhas $1 / 2$ Limousin $+1 / 2$ Nelore. Tese (Doutorado em Ciência Animal com ênfase em Produção Animal). Curso de Pós-graduação em Ciência Animal. Universidade Estadual de Londrina. 108 pp.

Getachew, G.; Blümmel, M.; Makkar, H.P.S. and Becker, K. 1998. In vitro gas measuring

Archivos de zootecnia vol. 62, núm. 237, p. 141. 


\section{FORTALEZA, SILVA, BARBERO, BARBOSA, CALSAMIGLIA E PRADO}

techniques for assessment of nutritional quality of feeds: a review. Anim Feed Sci Tech, 72: 261-281.

Jouany, J. P. 1982. Volatile fatty acids and alcohol determination in digestive contents, silage juice, bacterial cultures and anaerobic fermentor contents. Sci Alim, 2: 131-144.

Lana, R.P. 2007. Sistema Viçosa de formulação de rações. 4 ed. Editora UFV. Viçosa. 91 pp.

Martins, A.S.; Prado, I.N.; Zeoula, L.M.; Branco, A.F.e Nasciemnto, W.G. 2000. Digestibilidade aparente de dietas contendo milho ou casca de mandioca como fonte energética e farelo de algodão ou levedura como fonte proteica em novilhas. Rev Bras Zootecn, 29: 269-277.

Mauricio, R.M.; Mould, F.L.; Dhanoa, M.S.; Owen, E.; Channa, K.S. and Theodorou, M.K. 1999. A semi-automated in vitro gás production thechnique for ruminant feedstuff evaluation. Anim Feed Sci Tech, 79: 321-330.

Mauricio, R.M.; Pereira, L.G.R.; Gonçalves, L.C.; Rodriguez, N.M.; Martins, R.G.R. e Rodrigues, J.A.S. 2003. Potencial da técnica in vitro semiautomática de produção de gases para a avaliação de silagens de sorgo (Sorghum bicolor (L.) Moench). Rev Bras Zootecn, 32: 1013-1020.

Mello, D.F.; Franzolin, R.; Fernandes, L.B.; Franco, V.M. e Alves, T.C. 2008. Avaliação do resíduo de nabo forrageiro extraído da produção de biodiesel como suplemento para bovinos de corte em pastagens. Rev Bras Saúde Prod Anim, 9: 45-56. <http://revistas.ufba.br/ index.php/ rbspa/article/view/916/586> (13/06/ 2009).

Mizubuti, I.Y.; Pinto, A.P.; Pereira, E.S.e Oliveira, B.M. 2009. Métodos laboratoriais de avaliação de alimentos para ruminantes. EDUEL. Londrina. $226 \mathrm{pp}$.

Moreira, P.C.; Reis, R.B.; Rezende, P.L.P.; Mendonça, A.C.; Wascheck, R.C. e Martins, A.F. 2009. Produçao de ácidos graxos voláteis, avaliada pela técnica semiautomática in vitro, na dieta de ruminantes com diferentes fontes de carboidratos na fração volumosa. Ciênc Anim Bras, 10: 413-424.

Neiva Júnior, A.P.; Silva Filho, J.C.; Van Cleef, E.H.C.B.; Pinto, J.C. e Abdalla, A.L. 2010
Avaliação das silagens de capim-elefante aditivadas com nabo forrageiro, pinhão manso e tremoço, pela técnica de produção de gases. Ciênc Agrotec, 34: 1024-1030.

Nogueira, M.P. 2011. Fermentação in vitro da torta de dendê cultivado nas condições do cerrado. Monografia (Graduação em Agronomia). Universidade de Brasília. Brasília. $43 \mathrm{f}$.

Ørskov, E.R. 1988. Nutrición proteica de los ruminantes. Acribia. Zaragoza. 178 pp.

Pell, A.N.; Doane, P.H. and Schofield, P. 1997. In vitro digestibility and gas production. In: $34^{2}$ Reunião Anual da Sociedade Brasileira de Zootecnia. Juiz de Fora. Anais... SBZ. Viçosa.

Pell, A.N. and Schofield, P. 1993. Computerized monitoring of gás production to measure forage digestion in vitro. J Dairy Sci, 76: 1063-1073.

SAS Institute. 1994. SAS/STAT User's Guide. SAS Institute Inc. Cary.

Satter, S.D. and Slyter, L.L. 1974. Effects of ammonia concentration on rumen microbial protein prodution in vitro. Br J Nutr, 32: 199-210.

Sluszz, T. e Machado, J.A.D. 2006. Características das potenciais culturas matérias-primas do biodiesel e sua adoção pela agricultura familiar. In: 6ํㅡㄹ Encontro de Energia no Meio Rural, Campinas. Anais... <http://www.proceedings. scielo.br/pdf/agrener/n6v1/032.pdf> (15/11) 2010).

Sniffen, C.J.; O'Connor, J.D.; Van Soest P.J.; Fox, D.G. and Russell, J.B. 1992. A net carbohydrate and protein system for evaluating cattle diets: II. Carbohydrate and protein availability. J Anim Sci, 70: 3562-3577.

Theodorou, M.K.; Williams, B.A.; Dhanoa, M.S.; Mcallan, A.B. and France, J. 1994. A simple gas production method using a pressure transducer to determine the fermentation kinetics of ruminant feeds. Anim Feed Sci Tech, 48: 185-197.

Van Soest, P.J. 1994. Nutricional Ecology of the Ruminant. Cornell University Press. Ithaca.

Vargas, L.H.; Lana, R.P.; Jham, G.N.; Santos, F.L.; Queiroz, A.C. e Mancio, A.B. 2002. Adição de lipídios na ração de vacas leiteiras: parâmetros fermentativos, ruminais, produção e composição do leite. Rev Bras Zootecn, 31: 522-529.

Weiss, W.P. 1993. Predicting energy value of feeds. J Dairy Sci, 76: 1802-1811. 